\title{
Lesson Study and the construction of capital: empowering children through dialogic engagement.
}

David Allan, ${ }^{*}$ Faculty of Education, Edge Hill University, Ormskirk, UK Ella O'Doherty, Faculty of Education, Edge Hill University, Ormskirk, UK David Boorman, Faculty of Education, Edge Hill University, Ormskirk, UK Paul Smalley, Faculty of Education, Edge Hill University, Ormskirk, UK

*Corresponding author: david.allan@edgehill.ac.uk $\underline{\text { ORCID }}$

\begin{abstract}
This paper explores the use of Lesson Study in primary schools in England as a powerful tool for developing teachers' pedagogical knowledge, and for shaping teaching practices that encourage children's engagement. Through Lesson Study, a critical space for dialogic engagement is generated, wherein children contribute to, and shape, teaching and teacher learning. Teachers' perspectives of using Lesson Study were captured using 26 semi-structured interviews and Bourdieu's notion of capital was used to conceptualise and analyse the impact on children. It is proposed that Lesson Study generates opportunities for teachers to explore relations of power through dialogue between teacher and child.
\end{abstract}

Keywords: Lesson Study; Bourdieu; Cultural capital; Disaffection; Dialogic engagement 
This is a post-print version of Allan, D, O'Doherty, E., Boorman D. and Smalley, P. Lesson Study and the construction of capital: empowering children through dialogic engagement. Education 3-13. International Journal of Primary, Elementary and Early Years Education.

\section{Introduction}

Traditionally, teaching in England operationalised as a solitary profession, where a shared knowledge base was not a common feature (Hiebert et al. 2002, 3), and children's voices were unacknowledged as children were 'excluded from decision-making concerning issues of identity and the quality of their lives' (Shaw 2019, 806). The professional development of teachers has long relied upon introspection - reflective thinking and self-evaluation juxtaposed with perspectives beyond the classroom, such as observations by senior management, that merely act as snapshots of practice. In recent years, however, the potential for the classroom to operate as an arena for collaborative pedagogical development has grown, and teachers are more open to learning from their pupils (Hopkins 2014). Teachers are engaging in knowledge-generating experiences (Bjuland and Mosvold 2015) and innovative strategies that can transform the efficacy of teacher learning (Opfer and Pedder 2011). As such, these can impact on pedagogical knowledge, a term which we employ to refer to 'the specialised body of knowledge of teachers for creating effective teaching and learning environments for their students' (Guerriero 2017, 13). In this way, teachers reflect on, and evaluate, the impact of teaching practices on children, resulting in opportunities to challenge the many educational inequalities that are played out and perpetuated in schools, such as the social disadvantage that can create perceptions of cultural inferiority, particularly where children are deemed ill-equipped to compete academically (Allan and Duckworth 2018; Reay 2001; Willis 1978). Such perceptions can affect the extent to which children feel free to make choices and can impact on how and what these children learn in the classroom. Teachers' professional development, then, is often aimed at improving understanding in this area (Dudley 2012). 
This is a post-print version of Allan, D, O'Doherty, E., Boorman D. and Smalley, P. Lesson Study and the construction of capital: empowering children through dialogic engagement. Education 3-13. International Journal of Primary, Elementary and Early Years Education.

This paper explores the use of Lesson Study (LS) as a mechanism for sharpening teacher focus towards children's learning, and for providing a space for facilitating individual empowerment, where children's voices are recognised as a powerful tool for shaping the curriculum. Drawing on Pierre Bourdieu's concept of capital, we argue that whilst institutionally legitimised capital enables privilege in the classroom, LS functions as a tool for redressing inequalities through the redistribution of power, and the facilitation of a space, where voice enables the construction/acquisition of capital. We conceptualise voice as linguistic capital, and thus a key constituent of institutionalised cultural capital, and identify it in the agentic actions of the children undertaking LS as symbolic capital (Bourdieu, 1989). For some children, a perceived lack of capital can result in restrictive levels of agency within the school structure and thus poor engagement in learning. To counter this, children often disengage in an attempt to reclaim lost agency (Allan 2014)

Through the creation of a space for dialogic engagement, LS facilitates the capture of the voices of those seen to lack the necessary capital to fully engage in schooling. As such, it aims to improve understanding of children's engagement/disengagement within the classroom and can shape pedagogical knowledge and teachers' practices, wherein learning is often inferred from children's behaviour in the classroom. We argue that teachers' methods of teaching, and their professional learning practices, inform, and in turn are informed by, pedagogical knowledge (Opfer and Pedder 2011). 
This is a post-print version of Allan, D, O'Doherty, E., Boorman D. and Smalley, P. Lesson Study and the construction of capital: empowering children through dialogic engagement. Education 3-13. International Journal of Primary, Elementary and Early Years Education.

\section{Lesson Study}

Lesson Study is a collaborative strategy for developing teachers' pedagogical knowledge, wherein teachers investigate their own practice (Lewis, Perry, and Murata 2006). It has been used in schools in Japan since the 1870s (Dudley 2013) and was introduced to England around the end of the twentieth-century by Pete Dudley (Dudley 2014) who drew on Stigler and Hiebert's $(1999,150)$ proposal that it was 'a clear model for teacher learning and a clear set of principles or hypotheses about how teachers learn.' Whilst this claim to be 'clear' is arguably simplistic, and fails to demonstrate the complexity and enormity of how teachers learn, LS is developmental as it 'encourages teachers to challenge their existing thinking...[and] to learn from each other in ways that are often widely different from their day-to-day practices' (Allan et al. 2018, 161). It can open up possibilities for pedagogical knowledge development through a greater teacher-child connection, and an increase in the collaborative working of teachers, resulting in 'reduced feelings of professional isolation' (Cajkler et al. 2015, 192). This can lead to opportunities for risk-taking, where teachers 'experiment with teaching [yet remain] highly accountable to improving pupils' learning' (Dudley 2013, 108).

In the traditional Japanese model, 'teachers work in small teams to plan, teach, observe, analyze, and refine individual class lessons, called research lessons' (Cerbin and Kopp 2006, 250). Whilst there is often fidelity to this model, nuances can be seen and cultural distortion, based on different ontological approaches, is a prime feature of varying implementation (Stigler and Hiebert 1999). For instance, professional development using Japanese LS is arguably less of an individual venture but rather a whole-school approach to implementation. A typical LS lesson in Japan is conducted in a laboratory-like manner - open to many internal and external observers, such as parents and teachers from other institutions. Moreover, the English version 
This is a post-print version of Allan, D, O'Doherty, E., Boorman D. and Smalley, P. Lesson Study and the construction of capital: empowering children through dialogic engagement. Education 3-13. International Journal of Primary, Elementary and Early Years Education.

of LS utilises specific children, known as case pupils (Dudley 2013), as a focus for achieving the objectives of the lesson.

In the English model used in this research, a particular challenge for the children is identified (such as long division), along with three case pupils, chosen as representative of the larger cohort. Three teachers collaboratively plan a lesson to address the challenge and one delivers the lesson whilst the remaining two observe, concentrating on the case pupils. All three teachers and the case pupils then convene a post-lesson discussion to evaluate the teaching and its impact on the case pupils' learning (Fernandez and Yoshida 2004). To complement the process, an external agent (Dudley 2014) - such as a teacher from another school or a university academic - may also participate in part, or all, of the process to offer an outside perspective that encourages the teachers to think differently. The agent can bring experience and knowledge of LS beyond the institution to challenge the implementation. This external perspective is important as it improves the boundary-crossing opportunities for knowledge growth by encouraging the teachers to think about implications for learning beyond their institution (Engestrom 1987).

Lesson Study concentrates on the minutiae and thus prompts teachers to explore children's individual needs, such as gaps in their subject knowledge (Lewis 2002) or imbalances in the power dynamics between a child and the teacher. Capturing such detail requires closely observing the case pupils within the lesson, thus filtering out much of the sensory input that a teacher would experience. In general, a typical lesson has been described as 'a swiftly flowing river' (Lewis and Tsuchida 1999, 50) in which teachers are bombarded with stimuli, such as when attempting to address, monitor and observe the behaviour and progress of many individuals. In order to deal with this, teachers concentrate on what they feel is important by 
This is a post-print version of Allan, D, O'Doherty, E., Boorman D. and Smalley, P. Lesson Study and the construction of capital: empowering children through dialogic engagement. Education 3-13. International Journal of Primary, Elementary and Early Years Education.

'filtering out classroom information not deemed immediately critical to the teaching that is happening at any given moment' (Dudley 2013, 109). However, this is a problematic process as it is easy to miss (filter out) important learning opportunities or evidence of learning itself (ibid). Lesson Study thus facilitates an opportunity to metaphorically stem the 'flowing river' as the observing teachers aim to capture a segment of it in the form of the case pupils' engagement. As such, LS can enable teachers to explore the power dynamics between the child and the teacher, particularly where a power imbalance may be reproduced within the institution.

This intense focus on specific children has been argued as a tool for teachers to generate evidence on how some children may think and learn in particular classroom situations (Yoshida, 1999). It has been claimed that the collaboration and collegiality formed through engaging in LS helps teachers to 'become more effective at raising student achievement' (Kraft and Papy 2014, 477) and thus informs planning (Dotger 2011; Lawrence and Chong 2010). However, this can arguably be improved where, through dialogic engagement, pupil voice is used to enable children to play an active role in contributing to the teaching and learning.

According to Taylor and Kent $(2014,388)$, 'Dialogue is considered one of the most ethical forms of communication because it serves to mitigate power relationships, values individual dignity and self-worth, and tries to involve participants in conversation and decision-making.' Dialogic engagement, then, is about facilitating a space where communication is operationalised as a two-way process. This can enable children to contribute to their learning by vocalising what stimulates and engages them and illustrating how they conceptualise the world around them. As such, pedagogical knowledge can be strengthened as teachers are encouraged to challenge their existing professional values and beliefs on teaching, and on how students learn. In this way, the curriculum becomes tailored to actual needs and individual gaps 
This is a post-print version of Allan, D, O'Doherty, E., Boorman D. and Smalley, P. Lesson Study and the construction of capital: empowering children through dialogic engagement. Education 3-13. International Journal of Primary, Elementary and Early Years Education.

in the children's subject knowledge can be identified more readily, with resolutions negotiated through stronger teacher-child relationships. In the observations, the focus on case pupils presents teaching at the micro level whereupon teachers draw conclusions that inform the macro level (Dudley, 2014), and this process is strengthened with the children's involvement in the post-lesson discussion.

LS can thus function as an inclusive teaching methodology to empower marginalised children, particularly those disempowered by the teaching practices of the institution, as it facilitates a critical space wherein children can exhibit, or subsequently acquire, the necessary capital with which they can compete with their privileged peers. To conceptualise this, we explore the concept of capital using the writing of Pierre Bourdieu.

\section{Bourdieusian capital}

Bourdieu's concept of capital functions in society as 'a system of exchange' (Harker et al. 1990) and this is often replicated in schools and classrooms where it is a resource for the interchange of knowledge and socio-cultural experiences, thus contributing to the power dynamics interplay between children and the teacher. The three forms of capital, referred to as the 'conceptual triad' (Wacquant 1992, 25), are economic, social and cultural. As a crude definition, these capitals represent the exchange of metaphorical and literal goods; namely, money (economic), networks of people (social), and legitimated knowledge (cultural), for example, an understanding of the works of Shakespeare or of the compositions of Verdi. A clear instance of an exchange in teaching is that of the cultural and economic capital interplay. Teachers have knowledge (cultural capital) that is utilised to facilitate intellectual growth in others, and these teachers are remunerated with a wage (economic capital). For pedagogical 
This is a post-print version of Allan, D, O'Doherty, E., Boorman D. and Smalley, P. Lesson Study and the construction of capital: empowering children through dialogic engagement. Education 3-13. International Journal of Primary, Elementary and Early Years Education.

knowledge development, the interplay of teachers' cultural capital is used to synthesise knowledge and experiences, thus generating potential for the co-construction of knowledge.

Social capital in teaching can be seen through networking with other teachers - sharing lesson plans and ideas, for example, or using key contacts, such as a head teacher, to connect with a school. Both these forms of capital can be exchanged and interrogated through LS as it facilitates the in-depth sharing of knowledge and professional experience. In this way, LS can encourage teachers to challenge their beliefs and assumptions of children and their learning, and thus to construct knowledge that is relevant to them. For children, cultural capital is an exchange mechanism that can empower individuals through institutional recognition, particularly when it aligns with conformity. Those children whose perceived cultural capital complements that of the classroom are often empowered with opportunities for greater vocal expression, and thus can contribute to teaching and learning through dialogic engagement. But children will arguably exhibit varying levels of capital, depending on their habitus, which Bourdieu $(1977,85)$ describes as 'the system of dispositions (partially) common to all products of the same structures.'

Habitus can be seen as an inclination to act in a certain manner - a predisposition that brings with it assumptions, based on former experiences - and although children's agency can challenge this, it is often constraining (Reay 2004). Both teachers and children act in relation to the values, assumptions and capital (particularly cultural capital) that they have accrued through their experiences and these manifest as habitus. Habitus is influenced by socialisation and cultural and environmental stimuli, such as the 'norms, values and dispositions inculcated via the family, education and to a lesser extent the environment' (Burke et al. 2016, 2). In this way, children can be seen to exhibit a shared habitus in relation to their learning, and thus think 
This is a post-print version of Allan, D, O'Doherty, E., Boorman D. and Smalley, P. Lesson Study and the construction of capital: empowering children through dialogic engagement. Education 3-13. International Journal of Primary, Elementary and Early Years Education.

and act in similar ways. For instance, there is a tendency for individuals from lower socioeconomic backgrounds to illustrate a habitus that is comparatively constrained, particularly in relation to their privileged (often middle-class) counterparts, and this is often self-perpetuated (Bourdieu 1990). As such, the gulf widens between those who feel they can and those who believe they cannot engage in the legitimated capital domains. The detrimental consequence of this in schools is that many individuals continue to be marginalised, and thus unlikely to make dialogic contributions, due to their apparent lack of cultural capital. Cultural capital may be embodied, that is, 'woven into the schemes of perception,' or institutionalised; for example, a qualification that is 'state-sanctioned' (Atkinson, 2020, 108).

Whilst this structural determinist perspective may perceive the potential for capital exchange as heavily constrained, there is arguably much scope for greater transmission of legitimate cultural capital in schools (where individuals feel a stronger sense of belonging), particularly where a meritocratic approach is utilised as a tool for social mobility (Burke 2016, 10). In many ways, schools determine what constitutes capital and this is played out in a social context or a cultural field, such as the school itself, which represents a range of objective possibilities. In a cultural field, groups (or individuals) determine and legitimate capital. This produces and authorises specific discourses around capital and these are reaffirmed by those who exhibit it. For others, a perceived lack of capital results in a rejection of the field (Atkinson, 2020). Field is also fluid and may refer to broader type of structure, such as multiple schools that function similarly. In this way, individual schools will reproduce the notion of capital (Apple 1982). This illustrates the values within that field and such capital is legitimised and aligns with what are often class-based experiences. For instance, children's exposure to the arts, where artefacts are hierarchically categorised, often complements the values of the school and aligns with many middle-class children's experiences (Reay 2006). 
This is a post-print version of Allan, D, O'Doherty, E., Boorman D. and Smalley, P. Lesson Study and the construction of capital: empowering children through dialogic engagement. Education 3-13. International Journal of Primary, Elementary and Early Years Education.

In this way, the school reproduces these values and complements the habitus that many privileged children demonstrate (Bourdieu 1984). For others, however, such institutionalised capital can be exclusionary, subsequently marginalising those children whose dispositions fail to meet the criteria. Arguably, one aspect of the process of expressing legitimate capital is voice, where cultural capital is exchanged through dialogic engagement. Drawing on Bourdieu's (1984) conceptions of cultural capital, voice is thus identified as both embodied with aspects such as accent impacting on perception - and institutionalised in that it represents authority. In schools, teachers have a space for their own voice whilst for children this is a much more nebulous affair (Rouvali and Riga 2019). For individuals whose values align with those of the school, however, voice is explicitly recognised and validated. For the remaining children, cultural capital often needs to be acquired or constructed and whilst some achieve this eventually, others may never succeed in fitting in.

\section{Context for the research}

Between 2015 and 2017, the Education Endowment Foundation (EEF) implemented a large LS pilot in 181 schools in the north-west, the south-west, and the east of England. The schools were asked to adopt a version of LS that was adapted to the English context. In many ways, this differed from the arguably traditional Japanese model, such as in the use of case pupils and in the number of observers involved. Rather than opting for the 'laboratory approach' used in Japan - where observers can be parents, guardians, or other teaching staff both within and beyond the institution, and often numbering more than 20 (Lewis and Tsuchida 1999) - the English LS restricted the undertaking to the triad of teachers involved in the construction of the lessons (Dudley 2014). In this way, the implementation facilitated a space where the teachers could take ownership of the process, and where hierarchical structures would be set 
This is a post-print version of Allan, D, O'Doherty, E., Boorman D. and Smalley, P. Lesson Study and the construction of capital: empowering children through dialogic engagement. Education 3-13. International Journal of Primary, Elementary and Early Years Education.

aside. Whilst some schools involved the external specialists in the planning and evaluation, others merely used them for initial advice and training.

Drawing on the EEF pilot, our research utilised a cross section of the schools from the northwest to explore teachers' perspectives of LS in relation to pedagogical knowledge. The LS model used in this research involved three teachers, often with different roles, such as an NQT, a deputy head and a subject specialist in one triad; however, existing hierarchical structures within the institution were deemed irrelevant as all three teachers took ownership of the lesson. Each school decided on a focus for the lesson (for instance, fractions as a typical conceptual difficulty in a maths lesson) and two case pupils who typified this concern. Many of the case pupils were deemed to be struggling to engage with aspects of the teaching or were not engaging with the lesson at all.

After the lesson, the group discuss the progress of the teaching and the case pupils have the opportunity to express their voice. The outcome is used to shape the following lesson which one of the two observing teachers will deliver. There is variance, however, in whether the same lesson is delivered to another group or whether the LS team 'utilise the knowledge gained in the process to inform their understanding of the case students and, subsequently, of teaching' (Allan et al 2018, 160). For this study, all schools were concerned with developing knowledge of a particular group of children and a new plan was devised for each lesson.

The involvement of children in the post-lesson discussion, particularly where they can contribute to further planning, is both a popular and innovative strategy for teaching in England (O'Leary 2012). As such, 'Lesson Study provides the means of bringing research, theory and 
This is a post-print version of Allan, D, O'Doherty, E., Boorman D. and Smalley, P. Lesson Study and the construction of capital: empowering children through dialogic engagement. Education 3-13. International Journal of Primary, Elementary and Early Years Education.

practice into the planning and evaluation of specific lessons' (Ylonen and Norwich 2012, 302). The two teachers who observe do so in a manner that differs from typical observations by senior management or Ofsted as there is a shared ownership of the lesson. Thus, the LS group must take collaborative responsibility for its development and no single teacher can be seen to fail. The observers were advised that they should approach a lesson 'as if 'zoomed-in' on the case pupil and then pan back to allow a bigger group or the whole class to come into frame' (Dudley 2014, 10). The LS process is cyclical and once the third teacher has delivered a session the final post-lesson discussion and overall evaluation of this cycle will take place. One iteration is complete when all three cycles of LS have been undertaken. In our study, schools generally completed one cycle per term so that the full iteration (three cycles) extended over the academic year. The whole process comprised two iterations.

\section{Methodology}

We began the research using an exploratory framework and interviewed 26 teachers from various schools in the north-west of England. Our aim was to investigate the teachers' perceptions of engaging with LS and how it impacted on both their pedagogical knowledge, including what they thought best facilitated learning for children, and their teaching practices. In order to gather contextual information on how LS was implemented, we also conducted some observations of LS lessons and post-lesson discussions. Whilst these enabled us to ascertain a stronger impression of how LS was used, the data reported on in this article are primarily those captured in the interviews. The interviews lasted around 30-40 minutes and were semi-structured to facilitate an exploration of key points raised in the teachers' personalised responses. In this way, the teachers were free to discuss how they had 
This is a post-print version of Allan, D, O'Doherty, E., Boorman D. and Smalley, P. Lesson Study and the construction of capital: empowering children through dialogic engagement. Education 3-13. International Journal of Primary, Elementary and Early Years Education.

implemented LS and what impact they felt it had on both their pedagogical knowledge and on the children's learning. The following research questions initiated our investigation:

- What are teachers' perspectives on using LS as a tool for pedagogical knowledge development?

- How do teachers feel LS impacts on teaching and on children and their learning?

The participant represented teachers with a variety of experiences, such as long-serving teachers (over ten years), senior management (e.g. deputy heads), and NQTs (see Table 1). Table 1 provides a demographic overview of the participants. All names are pseudonyms.

\section{Table 1. Participant information}

\begin{tabular}{|l|l|l|}
\hline Name & Role & Years of experience \\
\hline Anne & Deputy head teacher & $10+$ \\
\hline Bill & Year 4 teacher & $1-3$ \\
\hline Connor & Maths leader & $10+$ \\
\hline Denise & Class teacher & $10+$ \\
\hline Elsie & Class teacher & $3-5$ \\
\hline Frank & Year 4/5 teacher & $1-3$ \\
\hline Grace & Year 2 teacher & $3-5$ \\
\hline Harry & Year 5 teacher/assistant head teacher & $5-10$ \\
\hline Isla & Year 6 teacher/English leader & $\mathbf{1 0 +}$ \\
\hline Jacqui & Year 5 teacher/English leader & $\mathbf{1 0 +}$ \\
\hline Kelly & Year 4/maths leader & $\mathbf{5 - 1 0}$ \\
\hline Lisa & Year 4/5 teacher & $\mathbf{1 0 + 3}$ \\
\hline Mary & Year teacher & \\
\hline
\end{tabular}


This is a post-print version of Allan, D, O'Doherty, E., Boorman D. and Smalley, P. Lesson Study and the construction of capital: empowering children through dialogic engagement. Education 3-13. International Journal of Primary, Elementary and Early Years Education.

\begin{tabular}{|l|l|l|}
\hline Nancy & $\begin{array}{l}\text { Year 3/4, deputy head teacher/English } \\
\text { leader }\end{array}$ & $\mathbf{1 0 +}$ \\
\hline Ollie & Year 5 teacher & $\mathbf{1 0 +}$ \\
\hline Peter & Year 6 teacher, English leader, KS2 leader & $\mathbf{1 0 +}$ \\
\hline Ruth & Year 5 teacher & $3-5$ years \\
\hline Sue & Year 4/5 teacher & $1-3$ \\
\hline Tracy & Year 6 teacher, KS2 leader & $\mathbf{1 0 +}$ \\
\hline Ursula & Year 5 teacher & $\mathbf{3 - 5}$ years \\
\hline Vanessa & Year 4 teacher/deputy head teacher & $\mathbf{5 - 1 0}$ \\
\hline William & Year 5 teacher & $\mathbf{1 - 3}$ \\
\hline Alice & Year 5 teacher/maths leader & $\mathbf{5 - 1 0}$ \\
\hline Beth & Year 5 teacher & $\mathbf{1 0 +}$ \\
\hline Cindy & Year 4 teacher & $\mathbf{1 0 +}$ \\
\hline Donna & Year 4 teacher & $\mathbf{1 0 +}$ \\
\hline
\end{tabular}

In addition to the interviews, some post-lesson discussions were also observed in which the case pupils contributed to the evaluation and any children who were seen to be disengaging were positioned in a way that enabled the teachers to explore possible marginalisation. In support of this approach, the focus from the schools lay on developing the children rather than on perfecting a lesson. The LS groups followed the case pupils through various lessons as they established a focus on pedagogical development and child-centred learning.

All interviews were transcribed and read through fully by the team to account for possible anomalies and to ensure consistency. The transcripts - and in particular the quotes used - were also checked with the teachers involved to ensure that the data was an accurate depiction of 
This is a post-print version of Allan, D, O'Doherty, E., Boorman D. and Smalley, P. Lesson Study and the construction of capital: empowering children through dialogic engagement. Education 3-13. International Journal of Primary, Elementary and Early Years Education.

their perspectives. After the identification of themes, including checking and re-checking for clarity, the data were then categorised using NVivo 10 and subsequently analysed in relation to the nodes identified by the researchers. A second-level analysis was conducted using the initial themes, whereby subthemes were coded and the researchers began to glean an interpretive perspective of the teachers' accounts of engaging in LS. For validity and reliability, the team cross-checked the themes against their own interpretations and a final consensus was arrived at (in conjunction with the teachers' verifications) that is believed to accurately depict what the data mean.

We draw on a Bourdieusian framework for understanding the data and how it relates to Bourdieu's conceptual use of capital. We therefore frame our analysis of LS as a field in which structure is reconfigured, and where the interplay between children's agency and school plays out. The concept of voice was seen to emerge as a mechanism for acquiring legitimate capital; therefore, the findings are categorised into the following areas:

- Misrecognition and the transformative experience

- Facilitating a critical space for the acquisition/recognition of capital

- Children's capacity to shape the curriculum

Although some of the quotes have been abridged, every attempt has been made to retain the original context and meaning.

\section{Findings}

Misrecognition and the transformative experience 
This is a post-print version of Allan, D, O'Doherty, E., Boorman D. and Smalley, P. Lesson Study and the construction of capital: empowering children through dialogic engagement. Education 3-13. International Journal of Primary, Elementary and Early Years Education.

According to the teachers, engaging in LS provided greater access to the children's learning; indeed, many felt that they understood the process more having listened to the them. Frank, for instance, suggests that the post-lesson discussion was particularly useful for gleaning an 'indepth insight into how children work, what they want, and what motivates them.' For others, the use of an intense and focussed observation of the children in a lesson, engaging with the activities, enabled them to concentrate on the minutiae in a way that was not possible for the delivering teacher:

One of the children in my class that was part of the study had real difficulty cutting things out. Because you are focussed on one child, or the other teachers were, then we picked that up really quickly. So, it's things like that I tend to notice now about children in the class (Jacqui).

[LS] gives us an opportunity to see how children react in different groups. I personally changed the grouping round in my classroom so I can see how different children work with other children. It's an opportunity that you don't ordinarily get in everyday lessons. I've seen how some children learn - some of the barriers to learning... Sometimes there's things you overlook...I'm able to see my classroom from a different perspective, which is good (Bill).

This 'zooming in' on children's learning, in conjunction with the teachers' intense collaborative working, was seen to be effective for identifying problematic situations:

You could just gain so much. You could see what the children weren't engaged in, when they would kind of clock off, and then you could see what activities they actually thought, oh no I'm gonna join in there with this one (Grace). 
This is a post-print version of Allan, D, O'Doherty, E., Boorman D. and Smalley, P. Lesson Study and the construction of capital: empowering children through dialogic engagement. Education 3-13. International Journal of Primary, Elementary and Early Years Education.

A common perception, identified by several teachers, was that the children could be misunderstood and their actions could easily be misidentified:

We had lots of misconceptions about them (Harry).

As a result of engaging in LS, some teachers felt they could more accurately diagnose what was happening and who the children were:

I'm seeing them more as individual people than as just a group of learners (Isla).

Many seemingly disaffected children were instead happy and engaging, albeit functioning in their own way. As such, children's behaviour was reconceptualised and a typical situation would see a (previously identified) disengaged child redefined as a thinking child

And you could see the children you always thought maybe weren't listening 'cos they're kind of daydreaming. But then, when they got down to the work, you got a chance to say, oh well, they have been listening (Grace).

The impact of this was powerful for the teachers and enabled them to acknowledge any former misrecognition:

Oliver seems very disengaged a lot of the time but he's actually opened my eyes to how much he does listen to me (Connor).

Situations like these were successful in facilitating greater reflection on personal teaching strategies and impacted deeply on pedagogical knowledge in the sense that some teachers identified a mismatch between what they believed was happening in the classroom and what they saw when observing the lesson. The teachers then began to challenge their existing understanding and, as a result, reconceptualised children's behaviours: 
This is a post-print version of Allan, D, O'Doherty, E., Boorman D. and Smalley, P. Lesson Study and the construction of capital: empowering children through dialogic engagement. Education 3-13. International Journal of Primary, Elementary and Early Years Education.

In terms of this one particular boy, who I now have in my class...I see him in a completely different light. He has behaviour problems and people kind of expect him to behave in a certain way [but] when we watched him in that lesson you could actually see that he was really trying (Isla).

This situation was facilitated by LS because it enabled the teachers to challenge the constraints of a typical lesson, particularly where 'a lot of your focus is on what you are delivering and how you are engaging the children' (Jacqui). Teachers reported having more time to think and to analyse the lessons whilst observing, and many claimed they could empathise more with the children. Some even suggested they were able to partially adopt a child's perspective:

It's understanding that the children's perceptions might not be what you think they should be (Connor).

\section{Facilitating a critical space for the acquisition/recognition of capital}

The opportunity for children to express their opinions and to voice their concerns was somewhat of a by-product of the LS process:

I wouldn't say that we don't listen to the children. But I think that whole pupils' voice has become more key for me (Isla).

As such, it became a prime focus for the cycles, and this resulted in teachers realising that their teaching could be more effective:

The thing that I found most useful was the post-discussion and the planning together - that willingness to take risks to do something that you wouldn't normally do (Nancy). 
This is a post-print version of Allan, D, O'Doherty, E., Boorman D. and Smalley, P. Lesson Study and the construction of capital: empowering children through dialogic engagement. Education 3-13. International Journal of Primary, Elementary and Early Years Education.

In this way, the teachers became less risk-averse and thus the concept of children contributing to the curriculum was deemed less of a threat. Any previously perceived notions that teachers should yield to pressures of performativity - such as those where the sole responsibility for learning lay on what the teachers did - were mitigated:

It's really easy to think well we'll just do this because we need to get to this assessment. But sometimes it is nice to take time to ask the children what they want to do (Grace).

Whilst many talk of the critical space as a means of giving the children a voice, it is clear that what is intended is the opening up of a dialogic engagement between the teachers and the learners. Thus, we would conceptualise the perception of 'giving the children a voice' as providing a critical space for the children to contribute to the teaching and learning.

In order to achieve the above objective of recognising voice, attempts were made to ensure the space was a productive one:

It might have been a bit formal at first so we tried to loosen it up and we tried to put tea and biscuits out and we'd all have a chat and that (Harry).

Decisions such as these were arguably empowering as the children were viewed in the same way as the staff. The teachers' actions were therefore crucial in encouraging the children to 
This is a post-print version of Allan, D, O'Doherty, E., Boorman D. and Smalley, P. Lesson Study and the construction of capital: empowering children through dialogic engagement. Education 3-13. International Journal of Primary, Elementary and Early Years Education.

respond in a thoughtful and accurate manner, particularly as they had previously been given stock responses:

Sometimes, answers we got were answers that they were trying to give you (Frank).

Before we began we thought they're just going to give teacher answers (Grace).

Sometimes we think the children maybe were telling us what they wanted us to hear (Harry).

Attempts were thus made to overcome this barrier:

We had to dig a bit deeper with them [and] this gave us the confidence to work this. And actually, they told us far more than we could possibly have imagined (Frank).

Ascertaining a voice that was more accurately representative, then, was a goal that many only achieved after undertaking a process of trust-building:

By the time we got to the third [post-lesson discussion], after the third lesson, they were a lot more vocal and were more keen to discuss it and share it, share their views. And I think it was because they felt more comfortable with it (Lisa).

This was believed to be particularly important as it was suggested that some of the children felt marginalised and unable to compete with their peers:

The underlying difficulty with the children that we chose was under confidence ....and they didn't feel like they had a place or right to have a voice. It's quite interesting because there was a lot of overbearing children in their group (Mary). 
This is a post-print version of Allan, D, O'Doherty, E., Boorman D. and Smalley, P. Lesson Study and the construction of capital: empowering children through dialogic engagement. Education 3-13. International Journal of Primary, Elementary and Early Years Education.

The teachers thus reflected on the children's situations and this impacted on their pedagogical knowledge as they challenged their former beliefs on facilitating an inclusive environment. Where children were now seen to be at a disadvantage, teachers adopted strategies such as identifying them as potential case pupils so that they could observe them in a different capacity. In this way, the teachers could generate potential for constructing new knowledge. This also redressed the balance somewhat as it enabled children who were not normally vocal to contribute:

Each child had a role and the children that were under-confident we gave them the speaker's role and the confident ones we gave the note-taker's role to stop certain children overpowering (Mary).

LS could thus empower pupils appropriately, as this teacher demonstrates:

He's really quiet. We thought he'd be really good for Lesson Study. It seemed to empower him [even though] interviewing him now could have intimidated him the fact that there were three adults asking him questions. But it didn't, it had the opposite effect. He liked having freedom to speak (Jacqui).

As a consequence of the children's newfound vocal space, in some situations the teachers commented on just 'how articulate... and how brutally honest they can be' (Frank).

\section{Children's capacity to shape the curriculum}

The teachers felt that the post-lesson discussion was a generative force for encouraging agency, describing it as 'giving the children freedom to say things' (Ursula). In this way, the disempowering constraints of the school system are resisted and the children become 
This is a post-print version of Allan, D, O'Doherty, E., Boorman D. and Smalley, P. Lesson Study and the construction of capital: empowering children through dialogic engagement. Education 3-13. International Journal of Primary, Elementary and Early Years Education.

empowered. The teachers found that the role of the case pupil enables the empowerment of particular children, such as those previously marginalised:

I chose a couple of children that seemed to go under the wire a lot (Ollie).

They just weren't engaging so we thought it'd be a good idea for us to try and get to know why (Kelly).

As a result of engaging in LS, the children are empowered, and the teachers begin to value their ideas and opinions, thus facilitating opportunities for the children to shape the curriculum:

...but really looking in detail at what they actually tell you, and using that to inform what you then plan in the future - that was a big thing for me (Isla).

They'd say what they liked and what they didn't like, and we'd go off and change it (Harry).

I think very often we assume quite a lot when we're planning our lessons. We think about what the children might need, but actually if you ask them they can give you a much bigger insight (Sue).

You probably ask them, 'How do you want to do something?' and they'll probably tell you. And it's probably a great idea, far better an idea than you previously thought (Frank). 
...it's allowing us to be more focused on the children and what we've found is it's becoming more apparent in our general classroom practice that the things we're picking up from Lesson Study are being applied to the lesson (Ollie).

\section{Discussion}

Many teachers are aware that the space for pupil voice is narrow, if not closed, and thus talk about 'giving' the children a voice (e.g. Connor/Isla). Whilst this may seem problematic, it illustrates that the teachers are challenging their pedagogical assumptions (Allan et al. 2018) and recognising that young people have agency and should be encouraged to draw on it (Reay and Wiliam 1999). This also presents opportunities for teachers to challenge the structural constraints of schools where 'the unacknowledged normality of the middle classes' (Reay 2006, 289) results in many non-privileged (often working-class) children not being at liberty to have an input in their learning, thus becoming passive recipients. Such children are often pathologized (Reay 2004).

Our study recognises that children possess the ability to raise relevant, interesting and thoughtprovoking concerns about their learning, and that this can impact strongly on teachers' pedagogical knowledge. Our argument is thus about facilitating the space for this to happen, as LS can do, and we suggest that in many situations this space is closed down, resulting in a metaphorical 'muting' of many voices and the loss of opportunity for teachers to construct relevant knowledge of their children. In particular, children of low socioeconomic status are likely to feel excluded from the teaching and learning process as they do not exhibit the necessary (institutionally legitimated) capital. Many even self-exclude due to these structural 
This is a post-print version of Allan, D, O'Doherty, E., Boorman D. and Smalley, P. Lesson Study and the construction of capital: empowering children through dialogic engagement. Education 3-13. International Journal of Primary, Elementary and Early Years Education.

constraints, resulting in a misalignment between their habitus and the field that they have bought into (Bourdieu 1984). As such, these children can feel that contributing to the curriculum is not a viable option for them (Bourdieu 1990). However, utilising them as case pupils can help to transform their outlook and to challenge their habitus.

\section{Empowerment}

In line with other studies, teachers found that through their use of LS they were able to improve relationships with colleagues and thus reduce their previously isolated teaching practices (Cajkler et al. 2015). The importance of this is that teachers can use these relationships to explore the nuances of teaching and learning, and to facilitate the empowerment of disaffected children and thus increase engagement (Allan 2015). Disaffection can set in where children are marginalised by a school's reproduction and (re)legitimation of cultural capital, and to address this, teachers can empower children to contribute to the curriculum, shaping teaching and informing decision-making (Hartas 2011). Through dialogic engagement, 'voice becomes a vehicle for validating unacknowledged capital' (Allan and Duckworth 2018,2) and thus functions as an important mechanism for change, where children can 'articulate their views and see through appropriate changes' (Fielding 2004, 199). Through LS, then, children actively contribute to learning in the classroom and to teachers' pedagogical knowledge development as teachers improve their understanding of how the interplay of the teacher-child power dynamics can impact on children's engagement.

Children perceived as lacking capital can become disaffected, often exhibiting 'a defeatist attitude towards their power for representation and decision-making [and being] less confident that their input would stimulate any substantive changes at school' (Hartas 2011, 106). As such, ingrained beliefs and values can impact on positioning a child within a social group, even if 
This is a post-print version of Allan, D, O'Doherty, E., Boorman D. and Smalley, P. Lesson Study and the construction of capital: empowering children through dialogic engagement. Education 3-13. International Journal of Primary, Elementary and Early Years Education.

such positioning conflicts with other people's perspectives of that child. There is, then, an initial job to be done in empowering such children and helping them to develop their selfesteem to a level where they feel that they can be included (Flutter \& Rudduck 2004). Children falling below the normative bar set by middle-class subjectivities have a tendency to experience marginalisation and behave in a manner that reflects their habitus (Bourdieu 1990; Reay 2006). To counter this, the case pupils in this study were empowered and thus acquired the linguistic capital previously afforded to others, helping them to feel that rather than being pathologized by the school (Reay 2006) they were in fact valued by it. For teachers, LS provides a new space for the critical exploration of ideas, where intense observations of nuanced behaviours during lessons, combined with the teacher-child dialogic engagement of post-lesson discussions, develops pedagogical knowledge (Lewis 2009).

\section{Impact on pedagogy}

The impact of including marginalised children and acknowledging their voices impacts on teachers' pedagogical knowledge as it influences their thinking and shapes their practice. In many ways, teachers' perceptions of children and their learning are reliant on information gleaned from the classroom; namely, that which is not filtered out (Dudley 2013). However, concentrating on one or two children during an observation, and then exploring their learning further through dialogic engagement, can capture information that otherwise may have been unavailable (Dudley 2014). For teachers, the sheer volume of stimuli they are confronted with means it is inevitable that much of what is not taken on board will unfortunately be useful. Engaging in LS, then, facilitates opportunities for teachers to concentrate on the minutiae, and to challenge their conceptions of the process of children's learning.

Whilst LS cannot tell us how learning occurs, focused observations of children during a lesson, 
This is a post-print version of Allan, D, O'Doherty, E., Boorman D. and Smalley, P. Lesson Study and the construction of capital: empowering children through dialogic engagement. Education 3-13. International Journal of Primary, Elementary and Early Years Education.

combined with the creation of a space for teacher-child dialogic engagement, helps teachers to better understand children's behaviour (Lewis 2009), and enables a more accurate identification of capabilities and specific learning requirements (Dudley 2013; Halvorsen and Lund 2013; Ylonen and Norwich 2012). Pedagogical growth, however, is sometimes determined as a by-product of this, even though it is often a key part of the process (Lewis 2009). For the LS cycle, the collaboration functions as a new field in which cultural capital is identified and nurtured - and one in which aspects of the non-privileged habitus are recognised and validated.

In many ways, the interrelationship between the children and the teacher can be conceptualised as a two-way transference of capital, and each develops in ways that are personally meaningful. The children's input into the post-lesson discussion is concentrated and relevant to them but there is also a necessity for valorisation of their voice. The negotiated process, then, is essential for the production of a deeper level of understanding - one which steers children into having relevant and meaningful input into the curriculum, and one which subsequently proffers a valuable contribution to pedagogical knowledge. Each stakeholder in LS (e.g. teacher, case pupil) plays a role but as a single entity they fail to capitalise on the strength of collaborative working and its potential for synthesising contributions to form new knowledge.

\section{Implications for school practice}

The teachers in this study have embraced the concept of pupil voice as a powerful tool for developing pedagogical knowledge (Hopkins 2014). They believe that observing the children in depth improved their knowledge of the role that a child plays in teaching and learning (O'Leary 2012), and this was reinforced with the teachers' interactions with the children in the 
This is a post-print version of Allan, D, O'Doherty, E., Boorman D. and Smalley, P. Lesson Study and the construction of capital: empowering children through dialogic engagement. Education 3-13. International Journal of Primary, Elementary and Early Years Education.

post-lesson discussion. Teachers are thus actively seen to challenge their existing pedagogical assumptions, particularly around children's learning (Bjuland and Mosvold 2015):

As a school, we've learnt to allow children to talk more and for us to talk to children more. I think we've learnt a lot about how to structure lessons, tailor-made to children... Listening to children, what they want, how they want to learn, and what suits them best...Also, allowing children to talk to each other as well and listening to their ideas and their understanding. It is something you don't always get a chance [to do] as a teacher on a daily basis whereas this has allowed us to have a really indepth understanding into what children were doing, what they were thinking, what their perceptions were (Frank).

Frank argues that LS's meritocratic approach to teaching, along with his intense interaction with the children, has resulted in a greater understanding of the children's needs. In this way, LS facilitates opportunities for the acquisition of capital and thus the potential for social mobility (Burke 2016, 10) and raised status within the school. The strong and effective bonds formed through such relationships occur more where teachers initially identify a gulf in their understanding of the children, particularly where it is believed that this gulf can be addressed through greater interaction. This also resonates with experienced teachers who see LS as 'a real eye-opener' (Isla) that generates knowledge in ways that were previously unavailable in the school.

Many of the teachers in this this study utilised the opportunity that LS affords to reconfigure the process of disempowerment that impacts on children with a perceived lack of capital, even in schools that purport to be child-focused. Operating on a meso level, schools are subject to 
This is a post-print version of Allan, D, O'Doherty, E., Boorman D. and Smalley, P. Lesson Study and the construction of capital: empowering children through dialogic engagement. Education 3-13. International Journal of Primary, Elementary and Early Years Education.

macro-level pressures of performativity that government policy dictates (Ball 2013) and involving children in teaching and learning may be considered somewhat of an indulgence. Our findings show, however, that in the micro level - where teachers implement policy according to the contextual needs of the school and their own professional values - LS can offer a grassroots-approach to challenging inequalities. Previously marginalised children will continue to be marginalised whilst their lack of capital constrains them, and this more often than not generates disaffection that leads to disengagement (Allan and Duckworth 2018). However, dialogic engagement facilitates the construction of capital within the system through the provision of a space where children can critically explore the curriculum and make valuable contributions. Moreover, LS aids the recognition of the previously marginalised children's values and thus identifies their existing capital as legitimate. These strategies thus contribute to the redistribution of legitimate capital as they empower children who for many years may have been unheard and undervalued.

\section{Conclusion}

Unlike in Japan, LS in England is not 'woven into the fabric of teachers' typical work schedules' (Lewis et al. 2013, 617) and it can be both time-consuming and costly. However, it is an effective tool for teachers to develop their pedagogical knowledge (Cerbin and Kopp 2006) as it can transform relationships, develop deep insights into children's learning, and facilitate opportunities for non-privileged children to contribute to teaching. Acting as a form of sociocultural currency, the acquisition of capital empowers children to a position whereby they can use their voice to exchange ideas and knowledge in return for status (Harker et al. 1990). This is a critical element of teaching and learning in that teachers can save time by stimulating children in a way that engages them to achieve (Kraft and Papy 2014). However, 
This is a post-print version of Allan, D, O'Doherty, E., Boorman D. and Smalley, P. Lesson Study and the construction of capital: empowering children through dialogic engagement. Education 3-13. International Journal of Primary, Elementary and Early Years Education.

whilst listening to children is a valuable and important strategy, such voices need to be valorised in order to fully shape pedagogical knowledge. It is, therefore, the synthesis of teacher-child experiences that generates knowledge that is relevant and functional.

While more research is needed to fully explore the implications of using LS, it does appear that it is more than just a useful strategy, with the benefits - greater collegiality, deeper understanding of children's needs, the embedment of research theory into everyday teaching activities (Ylonen and Norwich 2012), and the opportunity to raise the status for those previously used to lesser privileges - far outweighing the financial obstacle of three teachers working on one class/lesson on three occasions over an academic year. To build on this, further research that explores voice from the children's perspectives would arguably be a key strategy. This study captures the importance of pupil voice in relation to children's empowerment and thus makes a valuable contribution to our understanding of the production and reproduction of capital in the classroom.

\section{References}

Allan, D. 2014. "Dealing with Disaffection: The Influence of Work-Based Learning on 14-16Year-Old Students' Attitudes to School." Empirical Research in Vocational Education and Training 6 (10): 1-18. doi:org/10.1186/s40461-014-0010-4.

Allan, D. 2015. "Mediated Disaffection and Reconfigured Subjectivities: The Impact of a Vocational Learning Environment on the Re-Engagement of 14-16-Year-Olds.” International Journal on School Disaffection 11 (2): 45-65. 
This is a post-print version of Allan, D, O'Doherty, E., Boorman D. and Smalley, P. Lesson Study and the construction of capital: empowering children through dialogic engagement. Education 3-13. International Journal of Primary, Elementary and Early Years Education.

Allan, D., Boorman, D., O’Doherty, E. and Smalley, P. 2018. "Lesson Study.” In Becoming a research-informed school: Why? What? How? edited by T. Cain. London: Routledge.

Allan, D. and Duckworth, V. 2018. "Voices of Disaffection: Disengaged and Disruptive Youths or Agents of Change and Self-Empowerment?" British Journal of Special Education 45 (1): 43-60.

Apple, M.W. 1982. Education and Power. London: Routledge.

Atkinson, W. 2020. Bourdieu and After: A Guide to Relational Phenomenology. London: Routledge.

Ball, S. 2013. The Education Debate $2^{\text {nd }}$ ed. Bristol: Policy Press.

Bjuland, R. and Mosvold, R. 2015. "Lesson Study in Teacher Education: Learning from a Challenging Case." Teaching and Teacher Education 52: 83-90.

Bourdieu, P. 1989. “Social Space and Symbolic Power.” Sociological Theory 7 (1): 14-25.

Bourdieu, P. 1990. In Other Words: Essays Towards a Reflexive Sociology. Cambridge: Polity Press.

Bourdieu, P. 1977. Outline of a Theory of Practice. Translated by R. Nice. Cambridge: Cambridge University Press. 
This is a post-print version of Allan, D, O'Doherty, E., Boorman D. and Smalley, P. Lesson Study and the construction of capital: empowering children through dialogic engagement. Education 3-13. International Journal of Primary, Elementary and Early Years Education.

Bourdieu P. 1984. Distinction: A social Critique of the Judgement of Taste. Cambridge, MA: Harvard University Press.

Burke, C. 2016. "Bourdieu's Theory of Practice: Maintaining the Role of Capital." In Bourdieu: The Next Generation edited by J. Thatcher, N. Ingram, C. Burke and J. Abrahams. London: Routledge.

Burke, C., Thatcher, J., Ingram, N. and Abrahams, J. 2016. "Introduction: The Development of Bourdieu's Intellectual Heritage in UK Sociology." In Bourdieu: The Next Generation edited by J. Thatcher, N. Ingram, C. Burke and J. Abrahams. London: Routledge.

Cajkler, W., Wood, P., Norton, J., Pedder, D. and Xu, H. 2015. "Teacher Perspectives about Lesson Study in Secondary School Departments: A Collaborative Vehicle for Professional Learning and Practice Development." Research Papers in Education 30 (2): 192-213.

Cerbin, W. and Kopp, B. 2006. "Lesson Study as a Model for Building Pedagogical Knowledge and Improving Teaching." International Journal of Teaching and Learning in Higher Education 18 (3): 250-257.

Dotger, S. 2011. "Exploring and Developing Graduate Teaching Assistants' Pedagogies via Lesson Study.” Teaching in Higher Education 16 (2): 157-169.

Dudley, P. 2014. Lesson Study: A Handbook. Lesson Study UK. 
This is a post-print version of Allan, D, O'Doherty, E., Boorman D. and Smalley, P. Lesson Study and the construction of capital: empowering children through dialogic engagement. Education 3-13. International Journal of Primary, Elementary and Early Years Education.

Dudley, P. 2012. "Lesson Study development in England: From school networks to national policy.” International Journal for Lesson and Learning Studies 1 (1): 85-100.

Dudley, P. 2013. “Teacher Learning in Lesson Study: What Interaction-Level Discourse Analysis Revealed about How Teachers Utilised Imagination, Tacit Knowledge of Teaching and Fresh Evidence of Pupils Learning, to Develop Practice Knowledge and so Enhance their Pupils' Learning." Teaching and Teacher Education 34: 107-121.

Engestrom, Y. 1987. Learning by Expanding: An Activity-Theoretical Approach to Developmental Research. Helsinki: Orienta-Konsultit.

Fernandez, C., and Yoshida M. 2004. Lesson Study: A Japanese Approach to Improving Mathematics Teaching and Learning. Mahwah, NJ: Lawrence Erlbaum.

Fielding, M. 2004. “Transformative Approaches to Student Voice: Theoretical Underpinnings, Recalcitrant Realities.” British Educational Research Journal 30 (2): 295-311.

Flutter, J. and Rudduck, J. 2004. Consulting Pupils: What's in it for Schools? Abingdon: Routledge.

Guerriero, S. (ed) 2017. Pedagogical Knowledge and the Changing Nature of the Teaching Profession. Paris: OECD.

Halvorsen, A.L., and Lund, A.K. 2013. "Lesson Study and History Education.” Social Studies 104: 123-129. 
This is a post-print version of Allan, D, O'Doherty, E., Boorman D. and Smalley, P. Lesson Study and the construction of capital: empowering children through dialogic engagement. Education 3-13. International Journal of Primary, Elementary and Early Years Education.

Harker, R., Mahar, C. and Wilkes, C. 1990. An Introduction to the Work of Bourdieu. London: Macmillan.

Hartas, D. 2011. "Young People's Participation: Is Disaffection Another Way of Having a Voice?" Educational Psychology in Practice 27 (2): 103-115.

Hiebert, J., Gallimore, R. and Stigler, J.W. 2002. "A Knowledge Base for the Teaching Profession: What Would it Look Like and How Can We Get One?" Educational Researcher 31(5): $3-15$.

Hopkins, E.A. 2014. "Supporting Pre-Service Teachers to Enhance the Effectiveness of their Classroom Practice through Engaging with the "Voice" of their Pupils." Teacher Development 18(1): 15-28.

Kraft, M.A. and Papy, J.P. 2014. "Can Professional Environments in Schools Promote Teacher Development? Explaining Heterogeneity in Returns to Teaching Experience." Educational Evaluation and Policy Analysis 36 (4): 476-500 doi:10.3102/0162373713519496.

Lawrence, C.A. and W.H. Chong. 2010. "Teacher Collaborative Learning through the Lesson Study: Identifying Pathways for Instructional Success in a Singapore High School." Asia Pacific Educational Review 11 (4): 565-572.

Lewis, C. 2009. "What is the Nature of Knowledge Development in Lesson Study?" Educational Action Research 17 (1): 95-110. doi:10.1080/09650790802667477. 
This is a post-print version of Allan, D, O'Doherty, E., Boorman D. and Smalley, P. Lesson Study and the construction of capital: empowering children through dialogic engagement. Education 3-13. International Journal of Primary, Elementary and Early Years Education.

Lewis, C. 2002. "Does Lesson Study have a Future in the United States?” Nagoya Journal of Education and Human Development 1 (1): 1-25.

Lewis, J.M., Fischman, D. Riggs, I. and Wasserman, K. 2013. “Teacher Learning in Lesson Study.” The Mathematics Enthusiast 10 (3): 583-620.

Lewis, C., and Tsuchida. I. 1999. “A Lesson is Like a Swiftly Flowing River: Research Lessons and the Improvement of Japanese Education.” Improving Schools 2 (1): 48-56.

Lewis, C.C., Perry, R. and Murata, A. 2006. "How Should Research Contribute to Instructional Improvement? The Case of Lesson Study." Educational Researcher 35 (3): 3-14.

O’Leary, M. 2012. "Exploring the Role of Lesson Observation in the English Education System: A Review of Methods, Models and Meanings." Professional Development in Education 38 (5): 791-810.

Opfer, V.D. and Pedder, D. 2011. “Conceptualizing Teacher Learning.” Review of Educational Research 81 (3): 376-407.

Reay, D. 2001. "Finding or Losing Yourself?: Working-Class Relationships to Education." Journal of Education Policy 16 (4): 333-346.

Reay, D. 2004. “'It's all Becoming a Bit Habitus': Beyond the Habitual Use of Habitus in Educational Research.” British Journal of Sociology of Education 25 (4): 431-444. 
This is a post-print version of Allan, D, O'Doherty, E., Boorman D. and Smalley, P. Lesson Study and the construction of capital: empowering children through dialogic engagement. Education 3-13. International Journal of Primary, Elementary and Early Years Education.

Reay, D. and Wiliam, D. 1999. “'I'll be a Nothing': Structure, Agency and the Construction of Identity through Assessment.” British Educational Research Journal, 25 (3), 343-354.

Reay, D. 2006. "The Zombie Stalking English Schools: Social Class and Educational Inequality." British Journal of Educational Studies 54 (3): 288-307.

Rouvali, A. and Riga, V. 2019. “Redefining the Importance of Children’s Voices in Personal Social Emotional Development Curriculum Using the Mosaic Approach.” Education 3-13 47 (8): 998-1013. doi:10.1080/03004279.2018.1553990.

Shaw, P.A. 2019. “Engaging with Young Children's Voices: Implications for Practitioners' Pedagogical Practice." Education 3-13 47 (7), 806-818. doi:10.1080/03004279.2019.1622496.

Stigler, J.W. and Hiebert, J. 1999. The Teaching Gap: Best Ideas from the World's Teachers for Improving Education in the Classroom. New York: The Free Press.

Taylor, M. and Kent, M.L. 2014. "Dialogic Engagement: Clarifying Foundational Concepts." Journal of Public Relations Research 26 (5), 384-398, doi: 10.1080/1062726X.2014.956106.

Wacquant, L.J.D. 1992. “The Fuzzy Logic of Practical Sense.” In An Invitation to Reflexive Sociology, edited by P. Bourdieu \& L.J.D. Wacquant, 19-25. Cambridge: Polity Press.

Willis, P. 1978. Learning to Labour. London: Routledge. 
This is a post-print version of Allan, D, O'Doherty, E., Boorman D. and Smalley, P. Lesson Study and the construction of capital: empowering children through dialogic engagement. Education 3-13. International Journal of Primary, Elementary and Early Years Education.

Ylonen, A. and Norwich, B. 2012. "Using Lesson Study to Develop Teaching Approaches for Secondary School Pupils with Moderate Learning Difficulties: Teachers' Concepts, Attitudes and Pedagogic Strategies.” European Journal of Special Needs Education 27 (3): 301-317.

Yoshida, M. 1999. Lesson Study: An Ethnographic Investigation of School-Based Teacher Development in Japan. Unpublished doctoral dissertation: University of Chicago. 